\title{
$\mathcal{A} \boldsymbol{C A S E}$
}

or

\section{LOSS OF POWER}

OVER THE

\section{VOLUNTARY MUSCLES.}

Br JOHN BOSTOCK, M.D.

Read Dec. 23, 1817.

THE following case, which I submit to the notice of the Society, will perbaps not be read without some degree of interest, from the pathological information which it contains, although I am aware that, in the minds of those who witnessed its progress and termination, the great interest which it excited was principally derived from feelings of sympathy and commiseration.

Mr. H., a middle-sized and well-formed man, between thirty and forty years of age, who had enjoyed good health and possessed considerable activity both of body and mind, applied for medical advice, in consequence of a pain which he experienced in one of the lower extremities. Its sent 
was on the outside and a little above the knee, but it sometimes shot up to the hip: it was neither constant nor severe, but it seemed to be increasing, and he found that it produced a degree of stiffness in the limb, which rendered him less able to make any unusual exertion, as in skipping or running. He mentioned that some months before, he had slipped backwards down the stairs of a ship's cabin, but nothing more than a slight bruise seemed to be occasioned by the accident, and a considerable time had elapsed between the fall and the commencement of his present complaint; he did not himself attach any importance to the circumstance.

After an interval of two months, his power of moving the limb was perceptibly diminished; so that he had occasionally been in danger of falling, in consequence of his not being able to raise the foot sufficiently, in stepping over any thing or in going up stairs. Upon noticing more particularly his manner of walking, I was able to perceive a degree of dragging of the limb, arising from a loss of voluntary power over the action of the muscles. The pain in the mean time had advanced rather more towards the upper part of the thigh, but it was still neither constant nor acute. During the next two months the complaints continued slowly to increase; the pain of the limb was not indeed much more severe, it possessed its full share of sensibility to external impressions and was of the natural temperature, but he lost more and more 
the command over its motions; when he walked he dragged it after him in an awkward manner, and when he made an effort to raise the foot, it was brought up higher than he intended, or in an oblique direction. During this time there had never been any pain in the trunk of the body, nor upon a very minute examination, could any disease be deteeted in the spine. The general health, how ever, began to be a little impaired; the appetite declined, the bowels became irregular, and there was a tendency to an hæmorrhoidal affection.

After another interval of about two months, the other limb was perceived to be affected; Mr. H. lost, in some degree, the command over it, and he felt shooting pains about the kmee and the hip-joint. A new symptom now appeared, which was peculiarly distressing: when be had been sitting or lying for some time, and fiast put his feet to the ground, a sensation darted through the legs something similar to what we experience when the limbs are said to be asleep. This caused him to draw them up with an involuntary jerk, and, for a few momeats, he felt very acute pain from this kind of exertion. There was, however, no numbness of the limbs at other times, and when they were once firmly placed on the ground, the darting pain was no longer felt. Shortly after this period a new affection made its appearance, a difficulty in the articulation of particular words, and for the four next months, the affection of the speech and of the limbs 
continued to increase, so that he became unable to move without assistance, and his power of utterance was nearly lost; the bowels were very irregular, and there was some degree of general emaciation.

About eight months after the commencement of the complaint, the patient was, for the first time, seized with pain in the back of the head and neck, which was described as an acute, deep seated, darting sensation. It recurred in paroxysms, at uncertain intervals, and was, in some degree, relieved by lying down; it was observed, that after one of these attacks, all the other complaints were aggravated, and the functions considerably disturbed. In the mean time, the general affections were advancing with a slow but regular progress, and in addition to his other calamities, Mr. H. now began to experience a stiffness in his hands and arms, which at first prevented him from writing, and at length from performing the common offices of life. Some time after the commencement of the paroxysms described above, the deglutition became seit sibly affected, and soon afterwards there was a loss of power over the muscles of the jaws and the neck.

His situation was now so truly deplorable that a speedy termination to his existence was ardently hoped for by his friends; but he was destined to experience still greater sufferings. For the six 
following months his complaints continaed to increase, until he was reduced to a state of compite belpiessness. The motion of the lower exirenities and the power of articulation were entirely lost, and the action of the hands and arms was very nearly so, deglutition was become extremely difficult, and the jaws could only be open:d just so far as to receive between them a small tea-spoon. His head fell down upon his chest, uuless when artificialiy supported; there was a constant flow of saliva from the month, and he was fiequenily almost suffocated with mucus, or convulsed with the ineffectual efforts to expel it. He was occasionaily affected with violent shooting pains in all the limbs, and his whole body was become so rigid, that not only was he unable to perform any motion without assistance, but it required considerable force to bend his body, so as to place him in a chair, when he had been in bed, or to extend him in bed afier he had been for some time sitting in his chair. His nights were moreover restless, and he could not lie in one posture for any length of time withcut great uneasiness. A large part of the day was necessarily. occupied in taking in, by very small quantities and in a very slow manner, a sufficient quantity of nutriment to satisfy the calls of hunger. Yet notwithstanding this loss of voluntary power over the muscles, there was no numbness or i:mensibility of any part of the body, either to mechanical impressions or to changes of temperature, and all the external senses and the mental faculties remained un. 
injured; he exhibited a very considerable degree of ingenuity in contriving different methods of communicating his ideas to those around him, and at times manifested even a degree of cheerfulness.

Mr. H. was condemned to drag on this wretched state of existence for six months longer; the rigidity of the limbs increasing, his pains becoming more violent, the cough more harassing, the diffculty of deglutition every day threatening its total suspension, and his nights becoming more restless, yet his senses, both mental and corporeal, remaining unimpaired. For some time before his death, the upper extremities, as well as the lower, were entirely motionless, and the only method be had of expressing his wants was by pushing his body against a moveable staff, which communicated with a board, on which the letters of the alphabet were placed, and by varying the degrees of motion, the staff was made to point to the different letters.

About three months before his death, in addition. to the ordinary and now constant pains, Mr. $H$. had occasional paroxysms of a more violent kind. As far as we could understand his description, they commenced with an acute throbbing, which darted down the back of the head and neck, terminating in a complete rigidity of the whole body, and a temporary suspension of the faculties. He was always much debilitated by these attacks, and obviously worse after them, and it was immediately 
subsequent to a violent seizure of this kind that he expired. A few days only before his death, his sight became indistinct, and there was some degree of strabismus, but there was no other affection of any of the functions connected with the nervous system, and the intellectual faculties remained unimpaired to the last. The state of the spine was examined several times during the course of the disease, and at these examinations, Dr. M'Cartney and Mr. Christian of Liverpool assisted, but nothing morbid could be discovered in its forms or condi. tion. Various remedies were prescribed by myself, in conjunction with the above gentlemen, but of these I think it unnecessary to give any account, as no benefit was derived from them.

Permission was obtained to examine the body after death, and I accompanied Mr. Christian for this purpose, anxious to discover the physical cause of such a long continued and extensive train of complaints. We began by examining the brain, and every part of it was most minutely scrutinized, but without our meeting with any appearance which could be considered as morbid. We had already consumed so much time in this part of the examination, that we determined to remove the basis of the cranium and the cervical vertebræ for a more minute dissection at our leisure, but we were not a little surprised, after a very careful investigation of the whole, to find every thing apparently in a natural state. After a very accurate survey of 
every part, we thought that we observed a slight furrow across the spinal cord, as if it had been compresied by a transverse ligature, and this in the place where it passes under the ring of the atlas; and upon attentively noticing this part of the bone, it appeared a little thickened and of a yellowish colour. These appearances, however, were not very distinct, and the change of structure existed in so slight a degree, that it would probably have escaped ohservation, had any other morbid derangement presented itself to our notice.

In reviewing this case, perhaps the most remarkable circumstance is the want of correspondence between the degree of disease, and the morbid state of the parts as discoverable upon dissection. It was farther remarkable in the voluntary power being so totally destroyed in all parts, while the other functions connected with the nervous system, as far as we could judge, were nearly unimpaired. The power of the nerves to convey impressions from their extremities to the brain was nearly in its natural state, while their power in transmitting the acts of the will from the brain to their extremities was totally destroyed, yet there was nothing in the state of the brain which could throw any light upon this circumstance. The confident expectation of the medical attendants was, that some disease would have been detected at the base of the cranium or upper part of the spine; yet, except what has been stated with respect to the atlas, nothing of this 
kind was discoverect. Are we then to conceive that this slizht aifiection of the bone was the source of all the monid syc pionss, or are we to attribute the complinus to some disease existing in the lower part vi lie pistic? It is to be observed, that althous. the volumiuy motions of all linds were so conpleres interinted, all the involuntary motions were ciminned nearly in their natural state. The affection ot the chest and that of the intestines seeirell to depend almost entirely upon the defect of voluntary motion in these parts; for the ordinary action of the chest was periormed in the natural manner, and there were sereral circumstances which marle it probable that the difficulty which attended the evacuation of the bowels, arose principally from the want of co-operation in the muscles of the abdomen, and those connected with the rectum. In the last place, I may remark upon the peculiar rigidity of the voluntary muscles, a circumstauce which was independent of their being no longer under the control of the will; and this rigi!lity does not seem to have been what we ought to denominate spasm, because there was no permanent contraction in them. Whether they were contracted or relaxed, it was found equally difficult to bring them into the contrary state, and to this circumstance, as well as to the loss of voluntary power, many of the most distressing symptoms ought probably to be referred.

While there is so much obscurity concerning the physical cause of the train of symptoms which oc- 
10 DR. BOSTOCK ON LOSS OF VOLUNTARY POWER.

curred in this case, we cannot expect to obtain any correct knowledge of its pathology. Is it probable that it was entirely an affection of the voluntary muscles and not of the nervous system, in which the nerves transmitted their influence in the natural manner, but where the muscles were incapable of receiving it, or being acted upon by it? I am not aware that such a morbid condition of the muscles is recognised by nosologists; but $I$ think it will be dificult to account for the symptoms upon the supposition of their ariginating solely in a disease of the nervous system, and indeed except in so far as respects the faculty of volition, we have no decisive proof that the nervous system was in any way diseased. 